\title{
Vertical dipoles to detect self potential signals in a seismic area of southern Italy: Tito station
}

\author{
G. Colangelo $^{1,2}$, V. Lapenna ${ }^{2}$, and L. Telesca ${ }^{2}$ \\ ${ }^{1}$ Dipartimento Infrastrutture e Mobilità, Regione Basilicata, C. so Garibaldi, Potenza, Italy \\ ${ }^{2}$ Istituto di Metodologie per l'Analisi Ambientale, CNR., C. da S. Loja, Tito (PZ), Italy \\ Received: 15 June 2005 - Revised: 28 July 2005 - Accepted: 28 July 2005 - Published: 9 September 2005 \\ Part of Special Issue "Seismic hazard evaluation, precursory phenomena and seismo electromagnetics"
}

\begin{abstract}
Since 2000 the Institute of Methodologies for the Environmental Analysis (National Council of Research, Tito, Italy) installed a geophysical monitoring network able to detect geoelectric, geochemic and seismometric parameters in seismic areas of southern Italy. During this period a very large data-base of geophysical time series has been organized and it is actually available to assess robust statistical methodologies to identify geophysical anomalous patterns linked with local seismicity. To better understand the influence of rain and cultural noise on geoelectrical signals (Self Potential), during May 2004 we drilled in Tito station a $20 \mathrm{~m}$-depth hole to measure the SP vertical component. The array is characterized by five $\mathrm{Pb}-\mathrm{PbCl}_{2}$ electrodes put at different depths. The common electrode is fixed at $20 \mathrm{~m}$. In this work we present some electrical anomalies probably correlated with local seismic activity on vertical dipoles recorded in Tito station.
\end{abstract}

\section{Introduction}

The analysis of geophysical signals and robust satellite techniques for remote sensing of seismically active areas (Zhao et al., 1994; Park, 1997, Martinelli et al., 1997; Di Bello et al., 1998; Hayakawa et al., 2000; Tramutoli et al., 2001) can give important information about the relation between the state of stress and strain in a seismic active area. Earthquake precursory phenomena of geoelectric nature have been repeatedly reported. In particular, transient variation of the earth electric field have been observed prior to seismic activities (Johnston, 1997).

In this work we will focus our attention on the self potential (SP) signals which represents the measure of the potential voltage difference between two points on earth surface due to the presence of an electric field produced by natural

Correspondence to: L. Telesca

(ltelesca@imaa.cnr.it) sources distributed in the subsoil (Sharma, 1997 and references therein).

The SP method has found large application in geothermal, environmental, and engineering applications to locate and delineate sources associated with movement of fluids and groundwater (Ogilvy et al., 1969; Corwin and Hoover, 1979; Sharma, 1997 and references therein). Furthermore other significant applications can be found in the geophysical survey of volcanic and tectonic areas (Di Maio and Patella, 1991; Lapenna et al., 1994; Di Maio et al., 1997). The origin of self-potential in the subsurface is caused by a wide range of processes which are not well understood at this time. However the principal types of source mechanism are the electrofiltration potential, the thermoelectric potential, the electrochemical and mineralization potential (Sharma, 1997).

In near surface geophysics the most relevant phenomenon which could originate the self-potential anomalous field is known as electrofiltration or streaming potential. It refers to the electrical signals produced when a fluid flows in a porous rock as a consequence of a pore pressure gradient. The phenomenon is generated by the formation in the porous ducts of a double electrical layer between the bounds of the solid, that absorb electrolyte's anions, and cations distributed in one diffused layer, near the boards. When the fluid, subordinate to pressure gradient, flows, it transports a part of the cations, giving on one side an excess of positive charges. Then, it develops an electric field induced along the length of the duct and the associated streaming potential, that it is generated to the duct's ends.

In this research field, the greatest problem is the sporadic monitoring activities in time and space. A very weak point is also the current approach to time series analysis that makes no use of robust statistical methods to discriminate extreme events from random noise. Further, the lack of objective criteria to assess the precursory character of the geophysical anomalous signals makes the short-term predictions based on them poorly reliable (Cuomo et al., 2000). Altogether these shortages concur to explain the low scientific consensus 


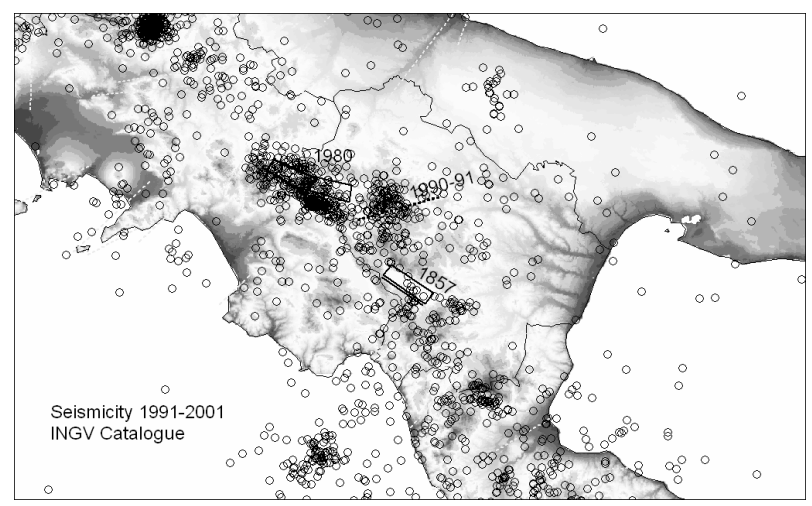

Fig. 1. Southern Apennine seismicity: 1991-2001. The investigated is characterized by a rather high seismic activity, with earthquake magnitudes not larger than 5 .

placed so far on the claimed correlation between the observed geophysical anomalies and the occurrence of earthquakes.

Taking into account these considerations, in this paper we present some examples of self-potential time series anomalies coming from a new geophysical monitoring network installed in a seismic active area of the Southern Apennine chain (Balasco et al., 2001). The aim of this monitoring network is to investigate the possible correlation between electrical anomalous patterns and local seismicity.

\section{Seismological setting}

The southern Apennines are an Adriatic-verging chain, built up from early Miocene to Pleistocene. It is mainly composed of sedimentary cover of platform and deep water environments, scraped off from the former Mesozoic Ligurian ocean, from the western passive margin of the Adriatic plate and from the Neogene-Pleistocene foredeep deposits of the active margin (Monaco and Tortorici, 1995; Schiattarella, 1998; Giano et al., 1999). Thrusting in the frontal eastern part of the accretionary wedge is followed by back-arc extension in the rear to the west. One of the evidence of active extension along the Apennines axis is widely documented in the field (e.g. Val dAgri, Vallo di Diano, etc.) and by seismicity (e.g. the 1980 Irpinia earthquake).

The architecture and the large-scale kinematics of the southern Apennines (Fig. 1) constructed a depth-extrapolated cross-section through the whole chain, from the Tyrrhenian Sea to the Adriatic (Apulian) foreland. Several tectonic units have been distinguished in the cross-section, moving from West to East, and from the top to the bottom of the chain. The Apulian cabonate platform has been incorporated by underplating at the base of the accretionary wedge. Restoration of the cross-section gave about $50 \%$ of shortening (corresponding to about $100 \mathrm{~km}$ ), not including the displacement related to the basal thrust of the Apenninic units on the Apulian platform. Shortening could be at least twice considering that the deformed "Apulian" units should be present at the base of

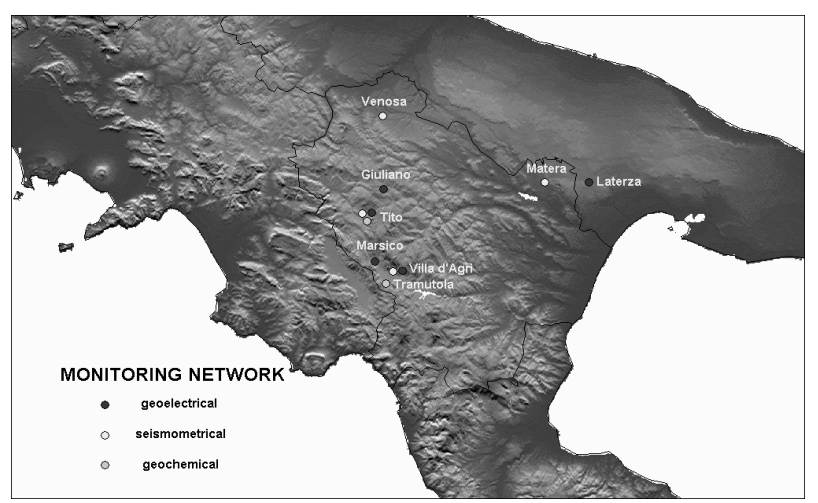

Fig. 2. Geophisical Monitoring Network: remote stations. The network covers a rather wide area in southern Italy. Our analysis has been performed on the geoelectrical data recorded at station Tito.

the whole accretionary wedge. Due to the time span estimated for the Apenninic orogeny (about $20 \mathrm{Ma}$ ), a very high shortening rate may be calculated $(1 \mathrm{~cm} / \mathrm{y})$.

From the seismological point of view, the CampanoLucano sector of the Southern Apennines chain is one of the most active areas of the Mediterranean region. In particular, this area is characterised by a probability $>60 \%$ to generate at least one earthquake with $M>3.5$ in a time span of 3 years (Martinelli and Albarello, 1997). In this region in February 1826, an earthquake, reaching up to VIII degree on the MCS scale (Alessio et al., 1995), hit the village of Tito where is located our prototype station. One of the most historically relevant events, the 16 December 1857 (I=XI MCS) normal-faulting earthquake (Mallet, 1862), occurred close to Marsico Nuovo village in Val d'Agri. On 23 November 1980 $(M s=6.9)$, a large normal-faulting earthquake occurred in the nearby Irpinia area. Seismic activity occurred after the 1980 event consisted of medium intensity events $(M<5.5)$ located close to the border between Campania and Basilicata regions (Alessio et al., 1995).

The 5 May $1990\left(M_{D}=5.0\right.$, ING-National Institute of Geophysics) and the 26 May $1991\left(M_{D}=4.7\right)$ earthquakes took place to the north of Potenza town (Tertulliani et al., 1992). These events have been generated by a strike-slip fault system with WE direction, perpendicularly oriented toward the Apennine chain (Ekström, 1994), located in such a way to limit toward north and south two great seismogenetic faults that caused the 1857 Val d'Agri and 1980 Irpinia earthquakes respectively. These geological and seismological features, combined with a very low level of cultural noise, allow us to consider the selected area as an ideal outdoor laboratory to study the possible correlations between tectonic activity and anomalous patterns in SP signals. Since the area is also characterized by seismic quiescence periods, in principle, it is possible to test alarms and false alarms. 


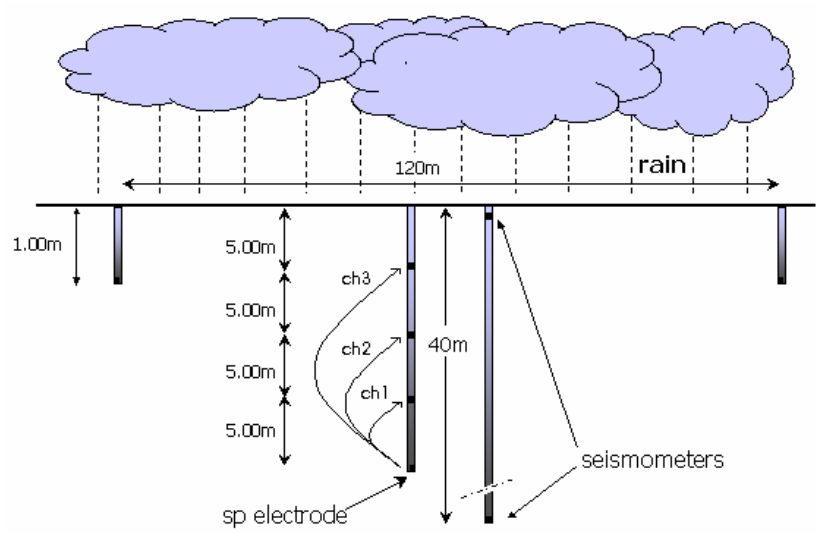

Fig. 3. Dipoles scheme of Tito station: 4 no-polarizable electrodes are put into the ground $1 \mathrm{~m}$ depth; with mutual distance of $120 \mathrm{~m}$ along NS direction and $100 \mathrm{~m}$ along EW direction. 5 no-polarizable electrodes are installed with a mutual spacing of $5 \mathrm{~m}$ along the well. The common electrode is fixed at $20 \mathrm{~m}$.

\section{Geophysical monitoring network: Tito station}

The geophysical monitoring network (Fig. 2) works since April 1999. We designed and installed the first remote station prototype to detect SP and seismometric signals in the Goephysical Laboratory (IMAA-CNR) located in Tito (Di Bello et al., 1994; Lapenna et al., 1998; Balasco et al., 2001; Colangelo et al., 2004; Telesca et al., 2005). We improved our monitoring network installing this prototype in six test sites of Southern Apennine chain: Tito, Giuliano, Val d'Agri area (Villa d'Agri, Marsico, Tramutola) and Laterza. All the remote stations are equipped with a multi-electrode array able to detect the time fluctuations of self-potential along at least in two directions: NS and EW. During the last years a very large data-base of SP time series has been organized and it is actually available to assess robust statistical methodologies to identify geoelectrical anomalous signals.

In this work we will describe the configuration of Tito station which is characterized by two kind of arrays to detect SP signals: vertical dipoles and horizontal dipoles (Fig. 3). The first type is characterized by 4 no-polarizable electrodes (Fig. 4) put into the ground $1 \mathrm{~m}$ depth; their mutual distance is $120 \mathrm{~m}$ for the 2 couples of electrodes in the NS direction and $100 \mathrm{~m}$ for the electrodes in the EW direction (the corners of a rectangular perimeter). With this configuration it is possible to evaluate the electric field irrotationality in real time, calculating the algebraic sum of the self-potentials recorded by the 4 channels (Colangelo et al., 2004). The SP electrodes are connected by screen cable to a high resolution multimeter and finally to a personal computer to store the data. The sampling rate is $\Delta t=1 \mathrm{~s}$. To better understand the influence of rain and cultural noise on SP signals, during May 2004 we drilled a hole of $20 \mathrm{~m}$ depth to measure the SP vertical component (Fig. 5). Five no-polarizable electrodes have been installed with a mutual spacing of $5 \mathrm{~m}$ along the well. The common electrode is fixed at $20 \mathrm{~m}$. The choice of the depth

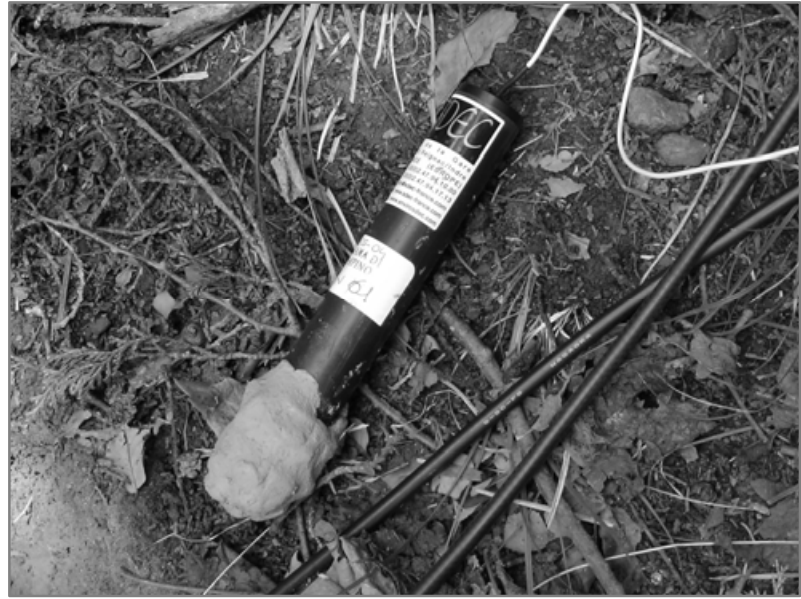

Fig. 4. No-polarizable electrode: $\mathrm{Pb}-\mathrm{PbCl}_{2}$.

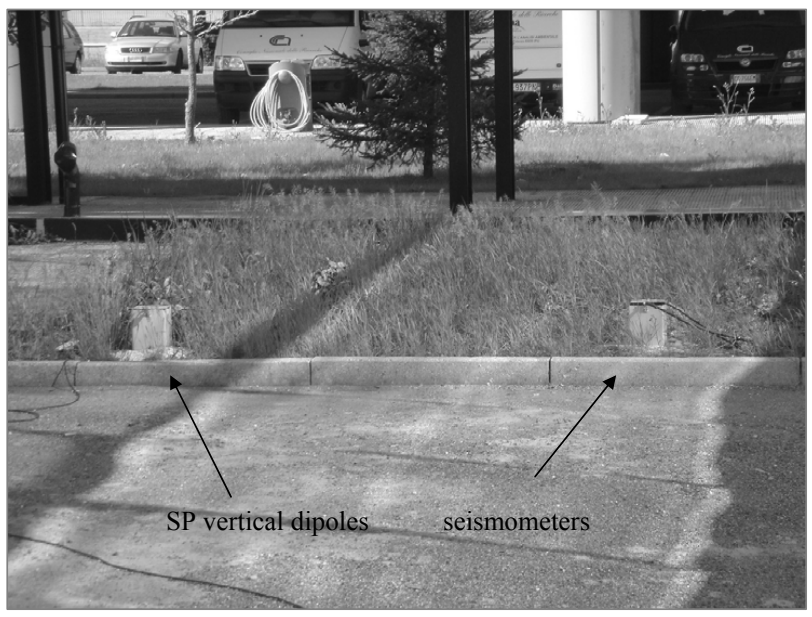

Fig. 5. Holes for the acquisition of SP and seismic signals.

spacing is due to technical settings. Figure $6 \mathrm{a}-\mathrm{b}$ show a few record examples of SP signals where it is possible to see the major stability of the signals on vertical dipoles.

\section{Preliminary results}

We presented the improvement of Tito station, where we jointly detect horizontal and vertical self-potential signals in a seismic active area of Southern Italy. Furthermore, we present some cases of possible correlation between the anomalous SP signals and local seismic events. The seismic events have been selected by the Dobrovolsky's rule (Dobrovolsky, 1993), that allows to select only the earthquakes, whose effect could produce variations in the geoelectrical parameters, detected into strain radius $r=10^{0.43 M}$, where $r$ is in $\mathrm{km}$ and $M$ is the magnitude of the earthquake. Figure $7 \mathrm{a}-$ b show an example of possible correlation between electrical anomalies and local earthquakes. During July 2004 an 
a)

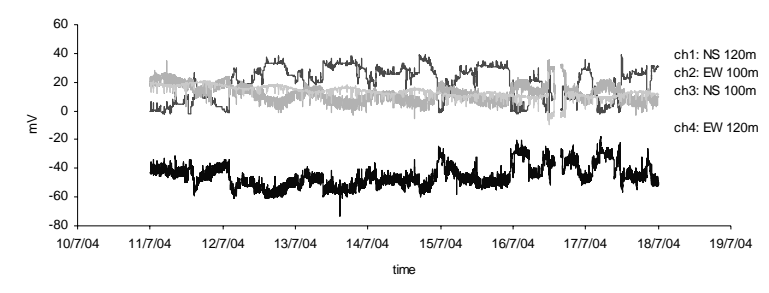

b)

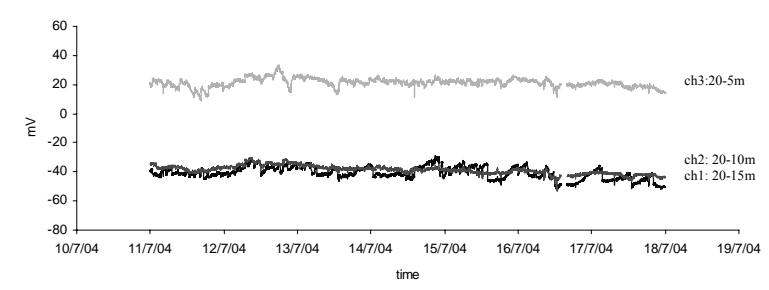

Fig. 6. Record examples of SP signals: (a) horizontal dipoles, (b) vertical dipoles. It is observable that the signal variability for the horizontal dipoles is larger than that for the vertical dipoles.

a)

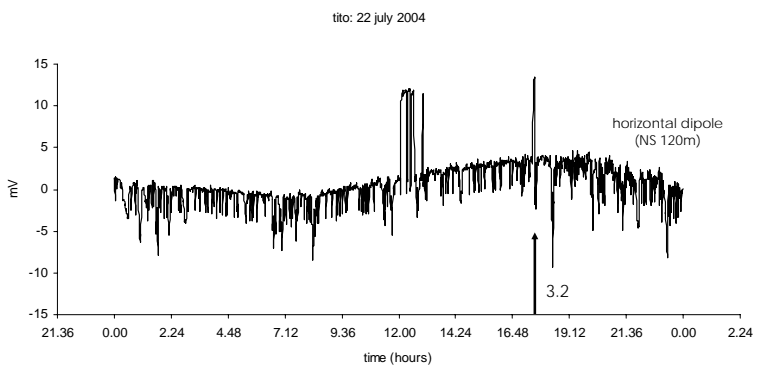

b)

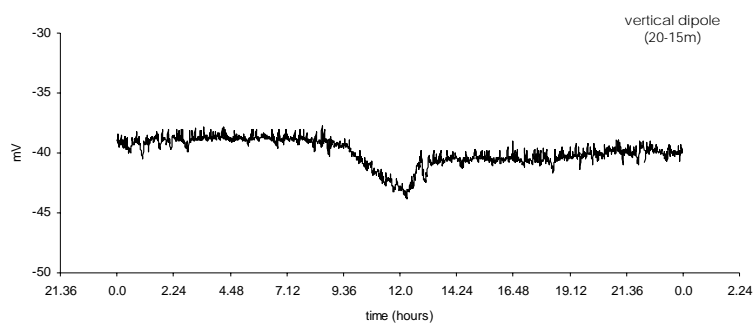

Fig. 7. SP signals during 22 July 2004. An earthquake of magnitude 3.2 occurred just few hours later the occurrence of anomaly in both the SP signals: (a) horizontal dipole, (b) vertical dipole.

earthquake very close to Tito station is occurred. Vertical and horizontal dipoles have detected anomalous fluctuations of self potential signals a few hours before the local earthquake with $M_{d}=2.8$. The horizontal dipole presents different pre-seismic geoelectrical anomalies and one co-seismic spike of $10 \mathrm{mV}$, while the vertical dipole shows a different shape of pre-seismic anomaly with an amplitude about $5 \mathrm{mV}$. During this time the geoelectrical signals are not influenced by rain events (Fig. 8). rain: july 2004

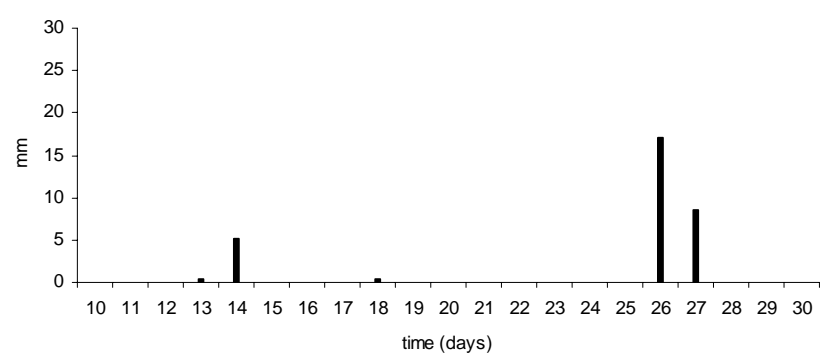

Fig. 8. Rain events occurred in July 2004.

We need long time series to give firm conclusions about the reliability of identifying possible geoelectrical precursors, nevertheless, the first results obtained encourage us to continue in this direction. In the next future we will increase the number of monitoring stations to detect vertical and horizontal electrical dipoles, by installing a large scale network covering the whole active seismic area of the Southern Apennine.

Edited by: B. F. Biagi

Reviewed by: Two referees

\section{References}

Alessio, G., Esposito, F., Gorini, A., and Porfido, S.: Detailed study of the Potentino seismic zone in the Southern Apennines, Tectonophysics, 250, 113-134, 1995.

Balasco, M., Chianese, D., Colangelo, G., Cuomo, V., Di Bello, G., Gallipoli, M., Lapenna, V., and Mucciarelli, M.: A new monitoring network to detect geoelectrical and seismometric signals in a seismic area of southern Italy, SeismoElectromagnetics: Lithosphere-Atmosphere-Ionosphere Coupling, edited by: Hayakawa, M. and Molchanov, O. A., TERRAPUB, Tokyo, 205-411, 2001.

Colangelo, G., Balasco, M., Lapenna, V., and Telesca, L.: Design and installation of a monitoring network to investigate the correlation between geoelectrical fluctuatuation and seismicity of Basilicata region (southern Italy), Phys. Chem. Earth, 29, 313320, 2004.

Cuomo, V., Di Bello, G., Lapenna, V., Piscitelli, S., Telesca, L., Macchiato, M., and Serio, C.: Robust statistical methods to discriminate extreme events in geoelectrical precursory signals: implication with earthquake prediction, Natural Hazards, 21, 247261, 2000.

Corwin, R. F. and Hoover, D. B.: The self-potential method in geothermal exploration, Geophysics, 44, 226-245, 1979.

Di Bello, G., Lapenna, V., Satriano, C., and Tramutoli, V.: Selfpotential time series analysis in a seismic area of the Southern Apennines: preliminary results, Annali di Geofisica, XXXVII, 5, 1137-1148, 1994.

Di Bello, G., Heinicke, J., Koch, U., Lapenna, V., Macchiato, M., Martinelli, G., and Piscitelli, S.: Geophysical and geochemical parameters jointly monitored in a seismic area of Southern Apennines (Italy), Phys. Chem. Earth, 23, 909-914, 1998. 
Di Maio, R. and Patella, D.: Basic theory of electrokinetic effects associated with earthquake, Boll. Geof. Teor. e Appl., 33, 130131, 1991.

Di Maio, R., Mauriello, P., Patella, D., Petrillo, Z., Piscitelli, S., Siniscalchi, A., and Veneruso, M.: Self-Potential, geoelectric and magnetotelluric studies in Italian active volcanic areas, Annali di Geofisica, 40, 519-537, 1997.

Dobrovolsky, I. P.: Analysis of preparation of a strong tectonic earthquake, Phys. Solid Earth, 28, 481-492, 1993.

Ekström, G.: Teleseismic analysis of the 1990 and 1991 earthquakes near Potenza, Annali di Geofisica, 37, 1591-1599, 1994.

Giano, I., Maschio, L., Alessio, M., Ferranti, L., Improta, S., and Schiattarella, M.: Radiocarbon Dating of the active faulting in the Agri High Valley, Southern Italy, J. Geodyn., 29, 371-386, 1999.

Hayakawa, M., Hattori, K., Itoh, T., and Yumoto, K.: ULF electromagnetic precursors for an earthquake at Biak, Indonesia on 17 February 1996, Geophys. Res. Lett., 27, 1531-1534, 2000.

Johnston, M. J. S.: Review of electric and magnetic fields accompanyng seismic and volcanic activity, Surveys in Geophysics, 18, 441-475, 1997.

Lapenna, V., Patella, D., and Piscitelli, S.: Tomographic analysis of self-potential data in a seismic area of Southern Italy, Annali di Geofisica, 43, 361-373, 2000.

Mallet, R.: The first principle of observational seismology as developed in the report to the Royal Society of London of the expedition made by command of the Society into the interior of the Kingdom of Naples to investigate the circumnstances of the great earthquake of December 1857, London (Reprnt Istituto Nazionale di Geofisica, Roma, 1987), 1862.

Martinelli, G. and Albarello, D.: Main constraints for siting monitoring networks devoted to the study of earthquake related hydrogeochemical phenomena in Italy, Annali di Geofisica, 40, 15051522, 1997.
Monaco, C. and Tortorici, L.: Tectonic role of ophiolote-bearing terranes in the development of the Shouthern Apennines orogenic belt, Terra Nova, 7, 153-160, 1995.

Ogilvy, A. A., Ayed, M. A., and Bogoslovsky, V. A.: Geophysical studies of water leakages from reservoirs, Geophys. Prosp., 22, 36-62, 1969.

Park, S. K.: Monitoring resistivity changes in Parkfield, California 1988-1995, J. Geophy. Res., 102, 24 545-24 559, 1997.

Patella, D.: Introduction to ground surface self-potential tomography. Geophysical Prospesting, 45, 653-681, 1997.

Schiattarella, M.: Quaternary tectonics of the Pollino Ridge, Calabria-Lucania boundary, southern Italy, in: Continental Transpressional and Transtensional Tectonics, edited by: Holdsworth, R. E., Strachan, R. A., and Dewey, J. F., Geological Society Special Publication, 135, 341-354, 1998.

Sharma, P. S.: Enviromental and engineering geophysics, Cambridge Univ. Press, 1997.

Telesca L., Balasco, M., Colangelo, G., and Lapenna, V.: Analysis of Extreme Events in Geoelectrical Time Series Measured in a Seismic Area of Southern Apennine Chain (Italy), Natural Hazards, 34, 177-198, 2005.

Tertulliani, A., Anzidei, M., Maramai, A., Murru, M., and Riguzzi, F.: Macroseismic study of the Potenza (Southern Italy) earthquake of 5 May 1990, Natural Hazards, 6, 25-38, 1992.

Tramutoli, V., Di Bello, G., Pergola, N., and Piscitelli, S.: Robust satellite techniques for remote sensing of seismically active areas, Annali di Geofisica, 44, 295-312, 2001.

Zhao, Y. and Qian, F.: Geoelectric precursors to strong earthquakes in China, Tectonophysics, 233, 99-113, 1994. 